\title{
The application of regression analysis on users' tolerance to prolonged waiting times: the case of KTM Komuter Services of Malaysia
}

\author{
S. Bachok, M. M. Osman, U. A. Khalid \& M. F. Zainaldin \\ Department of Urban and Regional Planning, IIUM, Malaysia
}

\begin{abstract}
Public transport routes and services are the vital movement agents in urban areas. Amongst issues of public transport performances are waiting times and transfer penalties incurred during multi-modal journey undertakings. This study has applied regression analysis on prolonged waiting times in order to quantify passengers' tolerance to inconsistencies in train departure and arrival times. Some 1000 users of KTM Komuter services, in Kuala Lumpur, Malaysia have participated in this study. The regression analysis model which is being developed shows that high tolerance to waiting times has been persistent among many commuters of the rail services. Several independent variables including socio-demographic and rail services characteristics have been found to have influenced this high level of tolerance. Other models have also been developed for variation to tolerance to punctuality (time arriving), modified ticketing systems, delays time, changing frequency, increased safety elements, and convenience levels. The analysis results have shown that if these inefficiencies and inconsistencies are not addressed in a timely and systematic manner, public transport services will experience more dwindling numbers of passengers in the near future. The models developed, are deemed to be useful for the services operators and regulators since they are planning and developing various systems improvements in the coming years to encourage mode switching behaviours from private vehicles to public transport use.

Keywords: public transport services, regression analysis, waiting time, KTM Komuter.
\end{abstract}




\section{Introduction}

The public transportation is mode of transportation that is frequently provided by the government. It includes various mode of transportation such as buses, subways, taxis, rails and ferry boats [1]. The services that been provided by the government ease the public's movement whether they live in urban or rural area. According to Dridi et al. [2] and Behwal and Behwal [3], public transport services must follow regular schedules, be safe and rapid, guarantee high service quality, utilize resources efficiently and meet users' demand.

In Malaysia, there exist many public transport systems such as trains, buses, taxis, trishaws and trains; including KTM Komuter, operated by Malaysian Railway. KTM Komuter is a heavy-rail public transport operator servicing the commuters from the suburban localities of Greater Kuala Lumpur region to the city centre. With an annual ridership of 36,557 million and daily passengers of nearly 90,000; KTM Komuter, has been one of the major public transport service providers in Malaysia [4].

Nowadays, traffic congestion is one of the major problems that confront many urban areas in Malaysia, including the Klang Valley area. Therefore, there is a need for the public transportation services to operate more effective and efficient in order to attract more people to use public transport as well as overcome the issue of traffic congestion. However, facing various challenges, most of the public transportation systems in Klang Valley area, especially, KTM Komuter cannot offer the quality of the services needed by passengers. KTM Komuter faces challengers such as delays, punctuality (time arriving), modified ticketing systems, delays time, changing frequency, increased safety elements, and convenience levels. The issues of public transports in Malaysia, in general, are becoming more widespread and services are below required levels, which could not satisfy the consumer needs and expectations [5].

Therefore, this study has applied regression analysis on prolonged waiting times to quantify passengers' tolerance to inconsistencies in train departure and arrival times. Additionally, other models have also been developed for variation to tolerance to punctuality (time arriving), modified ticketing systems, delays time, changing frequency, increased safety elements, and convenience levels, to a lesser effect. While addressing some major problems that occurred frequently which have resulted in lower satisfaction among the respondents.

\section{Literature review}

\subsection{Issues of public transport in Malaysia}

The most serious issue concerning the public transportation system is the lack of focus and coordination at all levels throughout the system. According to Shwarcz [6], at the national level the government does not actively promote public transportation and there is a lack of government focus on the issue. In the 8th Malaysia Plan, which is the government road map for development in Malaysia over the next several years, there is much emphasis on improving the quality of 
life in urban areas and a concern for environmental issues but there are few direct references made to public transportation. In addition, no single ministry or department oversees or is in charge of public transportation. Many agencies oversee various parts of the system, but there is no coordination between them and the state and local governments have no collective formal authority.

Shwarcz [6] also argued that there is a lack of integration at the system level between the various modes and within each mode. Infrastructure projects such as the LRT systems and the monorail were built without serious consideration of their role in the larger system. There are multiple bus companies but they do not serve as efficient feeder services to the light rail systems, nor are they coordinated with each other. Often there are multiple bus companies serving a single area, competing with each other, while other areas may have no services at all.

While, according to Zaherawati et al. [5], other examples of issues faced by public transport in Malaysia are the time arrival delaying in the Light Rail Transit (LRT) and Keretapi Tanah Melayu Berhad (KTMB) public transport modes. Users were less satisfied with the service quality provided by this public transports especially, in terms of punctuality and frequencies of train arrive. One factor contributing to this was the insufficient capacity to carry more passengers resulting in congested train services [7].

This issue showed that even if the public transportation is modernized, the service quality is still lacking and not well implemented. This will lead to negative perception and frustration among public transports users [8]. Other problems also faced by commuters and passengers included late buses. Despite the published scheduled of 15 minutes headways, users often had to wait at least a half an hour. These punctuality problems are the norms faced by many captive riders of public transportation in Malaysia [9]. Therefore, it is important that the services provided meet the users' demand to ensure the sustenance of the passengers in the longer term.

\subsection{Issues of public transport services regarding to KTM Komuter}

\subsubsection{Waiting time}

The first issue currently experienced by KTM Komuter users is the relatively long waiting time. Based on the survey conducted in this study, the maximum waiting time of 150 minutes was reported. Half of them were not able to board the first train during peak hours (morning and evening peak hours) and had to waited for up to the third train to continue the journey.

\subsubsection{Punctuality (departure and arrival time)}

According to Zaherawati et al. [5] punctuality, which is measured in terms of time arrival and departure, is an important element in defining the reliability of services. Currently, lack of punctuality has become a major issue in KTM Komuter services. Most of the users perceived that in terms of punctuality, arriving time has become worse. This problem frequently occurred during peak hours. According to Lester Kong [10] improving the reliability of the service by 
focusing on punctuality, will reduce door-to-door journey times, including invehicle and out-of-vehicle travel time during peak periods.

\subsubsection{Ticketing systems}

Several issues regarding ticketing system have been deemed essential for evaluation:

i. The independent ticketing and collection system for currently 16 different bus and rail operators across Klang Valley has caused many integration issues within the public transport systems.

ii. The average total travel time of a single journey has been excessively lengthened to include as much as $25 \%$ for queuing and waiting time for ticket purchase and/or arrival of vehicles.

The first problem regarding was due to the poor ticketing system, especially, during peak hour even after the implementation of using contactless card. The issues faced by commuters usually were those relating to inadequate ticketing counters and utilisation of ticket vending machines during peaks hours. These have increased waiting and overall journey time. Travel time has been in excess of 25 percent due to this additional waiting time for ticket transactions, in addition to, vehicles arriving late at the stations or platforms. In other words, to reach the destination at a designated arrival time, passengers have to begin the journeys $25 \%$ earlier than the normal departure time.

\subsubsection{Delays time}

Delay time for transit vehicles did not include dwell times at transit stops but the acceleration and deceleration delays at the transit stop is a part of the delay time itself. Delays time should be avoided to create a sustainable system so that the public transport could be more attractive to all commuters and overcome problems of congestion and delays which have direct costs on people and their activities.

Issues regarding on delays time are persistently associated with KTM Komuter. Usually, the delays time occurred due to inadequate provision of coaches and the low quality of the train sets (breakdown problems). Keretapi Tanah Melayu Berhad (KTMB) included high monetary cost maintaining the old coaches. Consequently, the maintenance and improving of the old coaches would take as long as six months to purchase the spare parts.

Another problem that faced the KTM was related to the performances of feeder services, which also increased travel time. For example, trains and buses frequently could not adhere to schedules and were often associated with unreliable service, frequent delays and cancellations. Commuters found it very challenging to plan ahead resulting in disruptions to their daily journeys undertaking.

There were suggestions that KTM should improve the train service in terms of punctuality and provide a suitable frequency (for example: every 10 minutes) in reducing congestion at the stations especially during peak hours. The other solution was to promote non-essential trip be made outside the peak periods so that the regular commuters could travel without any delays. 


\subsubsection{Frequency of train}

Switching to public transport is always dependent on the services frequency offered. This is important because suitable frequency provision by the KTM Komuter could reduce the congestion especially during peak hours. A study that illustrated in Singapore, the trains arrive every 3 to 5 minutes, compared to KTM Komuter, i.e. 15 minutes during peak hours and 30 minutes during off peak hours. Currently, with a train every 15 minutes during peak hours, it was usually sardine-packed especially when one train was delayed. It is not unusual for commuters to experience disrupted services, and whenever this happens during peak hours, the number of passengers would build up to the extent that the train carriages would be highly packed.

Missing a train by just two minutes could mean a loss of up to 45 minutes of waiting time in some instances, where the passengers have to take connecting trains or a shuttle bus. This automatically discouraged people from switching to public transport. Moreover, it will also affect their level of satisfaction of the current service provided, unless there was an increased frequency of the services.

Overcrowded situation in the coaches has also contributed to the increased waiting time. Overloaded coaches occurred when trains were unable to arrive according to the scheduled time, leading to further delays. Additionally, overloaded coaches could induce some problems such as inconvenience and vulnerable to safety (asphyxia).

\subsection{Stated choice surveys on waiting time}

Stated choice surveys are a gathering of respondents' statement about the preferences in a set of options. It is a marketing research tool with a set of alternative that were pre-specified attributes [11]. Another advantage of state choice surveys in that new proposed improvements or intervention can be assessed hypothetically without incurring the actual costs of implementation.

In other words, stated choice surveys are easy to control, more flexible and cheaper to apply [11]. However, a statement of a preference might not necessarily be translated into an actual behaviour or action. This is a disadvantage of this type of survey. Furthermore, people might have different comprehension levels regarding the questions posed to them, depending on the exposure, familiarity and reception towards surveys. The main disadvantage of stated preference survey is that travellers do not usually respond in an actual situation in a manner concurrent with their survey response [12]. All previous studies emphasised that relative journey times, delay on current route, age, sex and previous network knowledge as being important factors that govern travellers' route choice decisions. McArthur [13] found that diversion was based on whether time savings that travellers perceive lie above a threshold, as well as travellers' patience and trust in the system.

\subsection{Revealed preference surveys on waiting time}

Revealed preference surveys employed, in particular, recording of observed or actual behaviour or asking the respondents to recall on a specific action resulting 
from an event. Revealed preference provides more reliable and valid responses because choices are made and proven to be made explicitly.

However, the disadvantages of this type of surveys include being difficult to obtain an assessment of single attributes because choices were made based on interplay of all variables of interest. Second, even if, two variables can be isolated during the surveys, these variables could be strongly correlated such as distance and time or time and costs. Hence, it would be difficult to predict the effects of trade-off between these factors. Next, new or non-existence intervention could not be evaluated using revealed preference surveys. Finally, revealed preference surveys are better of determining the objective or engineering variables of transportation attributes such as time and costs, but would usually be impractical to measure latent variable such as comfort, convenience, safety and security [11].

Stated and revealed preference surveys have largely conducted using a set of carefully designed questionnaire. A questionnaire is a list of more or less structured questions that is given during the survey. Open questions require the respondent to write down his or her answers whereas closed questions provided either answer categories such as "like", "dislike" and "do not know" or a scale or rank could be provided on which value for the answer should be rated [14]. Both surveys can be conducted as one or a combination of the surveys which employed a structured questionnaire designed for a specific research purpose.

\subsection{The value of time}

The money value of time for non-work travel is the ratio of the marginal utility of time and the marginal utility of money. The former is made up of components attributable to the disutility of time spent travelling and to the opportunity cost of travel time.

Although the theory cannot give us precise guidance on how the value of time will vary over time, it can give us an indication of how it might change overtime. With regards to the money component, we would expect that income will grow over time, leading to a decrease in the marginal utility of money. As a result, the value of time should increase as income increases. However, beyond the direction of change, theory does not indicate the degree to which income will affect the value of time.

Additionally, the attribute used to measure travel costs (e.g. toll or petrol cost) may be perceived differently across time periods, again leading to changes in the money value of time over time.

The inter-temporal value of time will also be influenced by trends in the disutility of travel and the opportunity cost of travel, issues which tend to be ignored in official recommendations. The disutility of travel will fall over time as quality, comfort and facilities improve. Cars have become more comfortable over time and there have been improvements to in-car entertainment and environment. Public transport modes have also become more comfortable, with improvements in attributes such as interior decor, seating, ride quality and, in some instances, better onboard facilities and services. 
Appreciation of leisure has increased the trade of value of travel time. More productive travel time can now be ascertained by the deployment of smart phone and telecommuting, which in return have a significant downward influence on the value of time [15].

There might however be offsetting effects in certain circumstances. For example, urban car driving conditions are worsening whilst problems of crowding have heightened on some rail services into major conurbations. These would act to increase the disutility of time spent travelling.

\section{Study methodology}

\subsection{Data collection}

Primary data collection has been adopted for this research. Semi-structured questionnaire has been developed consisting of questions on passenger and trip characteristics. The respondents also provided their perceptions towards the current services. The questionnaires are distributed among the users on board the train from 21 November 2011 to 21 February 2012. Some 1,000 respondents have returned the completed questionnaire to the researchers.

\subsection{Statistical analysis}

The data from this research has been analyzed by using Statistical Package for Social Science (SPSS). The first step of the analysis was the exploratory data analysis where the data was examined and cleaned. All descriptive analyses were conducted for each variable. In determining correlation between any two variables, multivariate correlations have been applied. A regression analysis has been further undertaken to assess the factors influencing the waiting times among the users.

\section{Analysis}

\subsection{Descriptive analysis}

The questionnaire has been distributed to about 1000 respondents. The majority of the respondents' were age 15-25 years old that indicated $52 \%$ followed by age 26-35 years old (23\%). The minorities that cover about 5\% were from age 61-65 years old. Health level would differ based on their age and comfortable traveling is the main cause of this situation.

The survey indicated that there is a little contrast on gender that using KTM Komuter as transport mode with $58 \%$ of passenger were women. Furthermore, less than a third of respondent came from middle income level (RM1501RM2000).

In Table 1, park and ride and other stationed facilities have to a limited extent influence user's mode choice. A moderate majority of respondent had experienced delays while travelling on KTM Komuter. The maximum waiting time of 150 minutes was reported. Half of them were not able to board the train 
Table 1: $\quad$ Regression model.

Model Summary

\begin{tabular}{|c|c|c|c|c|}
\hline Model & $\mathrm{R}$ & R Square & Adjusted R Square & $\begin{array}{c}\text { Std. Error of the } \\
\text { Estimate } \\
1\end{array}$ \\
$.113^{\mathrm{a}}$ & .013 & .012 & 171.59319
\end{tabular}

a Predictors: (Constant), Time Used.

\begin{tabular}{|c|c|c|c|c|c|c|}
\hline \multicolumn{7}{|c|}{ ANOVA $^{b}$} \\
\hline \multicolumn{2}{|c|}{ Model } & $\begin{array}{l}\text { Sum of } \\
\text { Squares }\end{array}$ & df & Mean Square & $\mathrm{F}$ & Sig. \\
\hline 1 & Regression & 309241.888 & 1 & 309241.888 & 10.503 & $.001^{\mathrm{a}}$ \\
\hline & Residual & 2.388E7 & 811 & 29444.224 & & \\
\hline & Total & $2.419 \mathrm{E} 7$ & 812 & & & \\
\hline
\end{tabular}

Coefficients $^{\mathrm{a}}$

\begin{tabular}{|c|c|c|c|c|c|}
\hline \multirow[b]{2}{*}{ Model } & \multicolumn{2}{|c|}{$\begin{array}{l}\text { Unstandardized } \\
\text { Coefficients }\end{array}$} & \multirow{2}{*}{$\begin{array}{l}\text { Standardized } \\
\text { Coefficients } \\
\text { Beta }\end{array}$} & \multirow{3}{*}{$\begin{array}{c}\mathrm{t} \\
14.454\end{array}$} & \multirow{3}{*}{$\begin{array}{l}\text { Sig. } \\
.000\end{array}$} \\
\hline & B & Std. Error & & & \\
\hline (Constant) & 137.420 & 9.507 & & & \\
\hline TimeUsed & 5.438 & 1.678 & .113 & 3.241 & .001 \\
\hline
\end{tabular}

${ }^{\mathrm{a}}$ Dependent Variable: Waiting Time.

during peak hours (morning and evening peak hours) and waited up to the third train before finally being able to continue the journey.

Five factors had been identified as the most encouraging factors of the use of KTM Komuter; to avoid traffic congestion (43\%), accessible by public transport $(33 \%)$, wider destination and low fares $(10 \%)$, and shortened travel time $(5 \%)$. In term of train capacity, only one third of respondent are satisfied, $75 \%$ suggested to increase the number of coaches and $61 \%$ suggested to reduce seats on-board so that the train could accommodate more in one time. Majority of $47 \%$ had to wait for at least the second train (another 30 minutes) to complete their journey during peak hours. Captive riders, especially have higher tolerance to waiting time during peak hours compared to off peak hours.

\subsection{Regression analysis}

A regression analysis between years of experience using KTM Komuter services and duration of waiting times has been carried out. There are three decision rules for regression analysis. This was a bivariate regression. The dependent variable was waiting time, while the independent variable was duration years using KTM Komuter service. From Table 1 above, it can be seen that the three decision rules 
are the $r^{2}$ value, the significant level or $p$-value and the coefficient of intercepts. It can be seen that $r^{2}$ value (0.013) indicated a weak relationship between DV an IV. The coefficient $t$ of the intercept was 0.1 indicating that as years of experience increase by $10 \%$ the number of accidents will also increase by one unit. It can be concluded that $\mathrm{y}=5.438$ (years) +137 .

\subsection{Cross tabulation analysis}

Table 2 shows that the Contingency Coefficient value is 0.523 , which indicates a moderate relationship between the variables. Therefore, it can be said that the frequency of use did slightly influence the tolerance of prolonged waiting times for KTM Komuter. In terms of travel duration, Table 3 shows that the Contingency Coefficient value is 0.833 , which indicates a high relationship between total travel time and waiting time. Hence, it can be said that the longer time taken to wait for train did influence the travel time of passenger. Besides, different travel purposes also influenced the level of tolerance while waiting for

Table 2: $\quad$ Association between time used (per week) and waiting time.

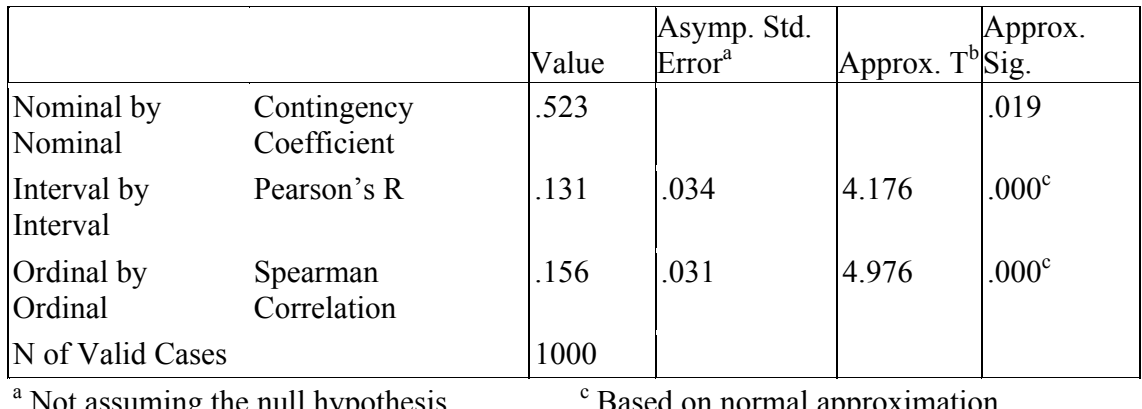

${ }^{a}$ Not assuming the null hypothesis.

${ }^{\mathrm{c}}$ Based on normal approximation.

${ }^{\mathrm{b}}$ Using the asymptotic standard error assuming the null hypothesis.

Table 3: $\quad$ Association between travel time and waiting time.

\begin{tabular}{|c|c|c|c|c|c|}
\hline & & Value & $\begin{array}{l}\text { Asymp. Std. } \\
\text { Error }^{\mathrm{a}}\end{array}$ & Approx. $\mathrm{T}^{\mathrm{b}}$ & $\begin{array}{l}\text { Approx. } \\
\text { Sig. }\end{array}$ \\
\hline $\begin{array}{l}\text { Nominal by } \\
\text { Nominal }\end{array}$ & $\begin{array}{l}\text { Contingency } \\
\text { Coefficient }\end{array}$ & .833 & & & 1.000 \\
\hline $\begin{array}{l}\text { Interval by } \\
\text { Interval }\end{array}$ & Pearson's R & -.031 & .029 & -.983 & $.326^{\mathrm{c}}$ \\
\hline $\begin{array}{l}\text { Ordinal by } \\
\text { Ordinal }\end{array}$ & $\begin{array}{l}\text { Spearman } \\
\text { Correlation }\end{array}$ & .005 & .031 & .167 & $.868^{\mathrm{c}}$ \\
\hline \multicolumn{2}{|c|}{$\mathrm{N}$ of Valid Cases } & 1000 & & & \\
\hline
\end{tabular}

${ }^{\mathrm{a}}$ Not assuming the null hypothesis. $\quad{ }^{\mathrm{c}}$ Based on normal approximation.

${ }^{\mathrm{b}}$ Using the asymptotic standard error assuming the null hypothesis. 
train. For example, users with shopping and sightseeing purposes have higher tolerance to waiting longer time compared to those with working and education purposes.

In Table 4, a moderate relationship between the numbers of trains passengers had to wait for before resuming a journey during peak hours and waiting time (0.624). Therefore, the number of trains waited during peak hours did slightly influence the waiting time, due to the frequency of KTM Komuter which ranged from 20-30 minutes.

Table 4: Association between number of train waited (during peak hours) and waiting time.

\begin{tabular}{|c|c|c|c|c|c|}
\hline & & Value & $\begin{array}{l}\text { Asymp. Std. } \\
\text { Error }^{\mathrm{a}}\end{array}$ & $\begin{array}{l}\text { Approx. } \\
T^{\mathrm{b}}\end{array}$ & $\begin{array}{l}\text { Approx. } \\
\text { Sig. }\end{array}$ \\
\hline $\begin{array}{l}\text { Nominal by } \\
\text { Nominal }\end{array}$ & $\begin{array}{l}\text { Contingency } \\
\text { Coefficient }\end{array}$ & .624 & & & .000 \\
\hline Interval by Interval & Pearson's R & .093 & .033 & 2.949 & $.003^{\mathrm{c}}$ \\
\hline Ordinal by Ordinal & Spearman Correlation & $\begin{array}{l}148 \\
1000\end{array}$ & .031 & 4.742 & $.000^{\mathrm{c}}$ \\
\hline
\end{tabular}

${ }^{a}$ Not assuming the null hypothesis.

${ }^{\mathrm{c}}$ Based on normal approximation.

${ }^{\mathrm{b}}$ Using the asymptotic standard error assuming the null hypothesis.

Table 5: Association between number of minutes tolerated for train (during peak hours) and waiting time.

\begin{tabular}{|l|l|l|l|l|} 
& Value & $\begin{array}{l}\text { Asymp. Std. } \\
\text { Error }^{\mathrm{a}}\end{array}$ & $\begin{array}{l}\text { Approx. } \\
\mathrm{T}^{\mathrm{b}}\end{array}$ & $\begin{array}{l}\text { Approx. } \\
\text { Sig. }\end{array}$ \\
\hline $\begin{array}{l}\text { Nominal by Contingency } \\
\text { Nominal }\end{array} \quad \begin{array}{l}\text { Coefficient } \\
\text { Interval by Interval Pearson's R }\end{array}$ & .690 & & & .000 \\
$\begin{array}{l}\text { Ordinal by Ordinal Spearman Correlation } \\
\text { N of Valid Cases }\end{array}$ & .140 & .037 & 4.463 & $.000^{\mathrm{c}}$ \\
\hline
\end{tabular}

${ }^{\mathrm{a}}$ Not assuming the null hypothesis. $\quad{ }^{\mathrm{c}}$ Based on normal approximation.

${ }^{\mathrm{b}}$ Using the asymptotic standard error assuming the null hypothesis.

Table 5 shows that the Contingency Coefficient value is 0.690 , which indicates a moderate relationship between variables. Therefore, the number of minutes tolerated for train during peak hours had slightly influenced the waiting time. 


\section{Synthesis of research}

The research aimed at quantifying passengers' tolerance to inconsistencies in train departure and arrival times with the application of regression analysis. According to the findings, there were some measurements that are needed to improve and increase the effectiveness of KTM Komuter services.

Further, regularly, the three coaches being continuously packed with passengers indicated the high demand for KTM Komuter services. Thus, additional numbers of coaches were highly recommended to accommodate numerous passengers at one time.

Home and work were the highest activity before and after the trips proving that KTM Komuter was an alternative transport mode to avoid congestion both at morning and evening peak hours. Thus, spending on KTM Komuter maintenance, improvement and development were necessary to encourage more public transport switching and thus lessening number of private vehicles on the road. Improved punctuality of services was able to attract more choice modes.

The research finding shows that waiting time including the time taken to purchase a ticket which could take up to 15 minutes due to Ticket Vending Machine (TVM) failure. Majority of respondent were unhappy with the long waiting time for train arrival. Delays, cancellation and rescheduling of trips were common which increased the pressures of commuting among users. Regular maintenance of locomotives and EMUs, new technologies, punctuality and frequent services are suggested in improvements areas.

\section{Conclusions}

Longer travel time on public transportation worsened KTM Komuter conditions over time. The KTM Komuter users' perceptions' on the current services have put forward several recommendations to improve the effectiveness of the KTM Komuter services. Two main objectives have been achieved by identifying waiting time in minutes and factors explaining the higher tolerance levels to waiting among respondents of this case study. This research finally contributed to knowledge by identifying, analysing and confirming the existence of prolonged waiting times in order to quantify passengers' tolerance to inconsistencies in train departure and arrival times.

The recommendations and suggestions assisted by strong justifications, modellings and simulations will indeed assist the service providers KTM Komuter, decision makers, stakeholders and responsible authorities in providing a better and more efficient public transportation system. While for public transport users, the suggested alternatives will help them visualize the best alternatives for the operations' benefits.

\section{References}

[1] Tran, T., and B. H. Kleiner. (2005). Managing for excellence in Public transportation. Management Research News 28(11/12): 154-163. 
[2] Dridi, M., K. Mesghouni, and P. Borne. (2005). Traffic control in transportation systems. Journal of Manufacturing Technology Management 16 (1): 53-74.

[3] Behwal R. and Behwal S. (2010). Public Transportation Services in Oman: A Study of Public Perceptions, Journal of Public Transportation, Vol. 13, No. 4: 2010.

[4] Number of Passengers for lightrail transit (LRT Services), (1999-2008), MOT.

[5] Zaherawati Z., Zaleha H., Mohamed Fajil AB., and Zuriawati Z. (2010). Service Quality of Malaysian Public Transports: A Case Study in Malaysia, Cross-Cultural Communication, Vol. 6, No. 2: 84-92.

[6] Shwarcz S. (2003). Public Transportation in Malaysia: 1-24.

[7] Utusan. (2008, August 25). Utusan Malaysia Online. Retrieved January 15, 2009, www.utusan.com.my

[8] Thompson, K. Schofield, P. (2002). Total Quality Service. A simplified Approach to Using the Baldrige Award Criteria. Kuala Lumpur: First Agency Press.

[9] The Malay Mail. (2009, April 11). Fed up with KTM Komuter delays. Retrieved May 28, 2011. www.malymail.com.my

[10] Lester Kong, 2010; http://klnportal.kln.gov.my

[11] Kroes, E., and R. Sheldon. 1998. Stated Preferences Methods: An Introduction. Journal of Transport Economics and Policy 22: 11-25.

[12] Rathi, V., Antoniou, C., Ben-Akiva, M. And Wen, Y. 2008. Optimal Variable Message Sign Location Identification Using Genetic Algorithms And A Close-Loop Simulation Environment, Proceedings of the $10^{\text {th }}$ International Conference on Application of Advanced Technologies in Transportation, Athens, Greece.

[13] McArthur, D. 1995. The Paramics-CM (Parallel Microscopic Traffic Simulator For Congestion Management) Behavioural Model. $23^{\text {rd }}$ European Transport Forum: Transportation Planning Methods: Proceeding Seminar E, London, PTRC Education and Research Services.

[14] Dziekan, K. (2008). Ease-Of-Use In Public Transportation - A User Perspective On Information And Orientation Aspects, PhD Thesis, Royal Institute of Technology Stockholm, Sweden.

[15] Gunn, H. (2001) Spatial and Temporal Transferability of Relationships between Travel Demand, Trip Cost and Travel Time. Transportation Research Part E, 37, pp. 163-189. 